\title{
The prevalence of malaria among HIV seropositive individuals and the impact of the co- infection on their hemoglobin levels
}

\author{
Sammy CK Tay ${ }^{1 *}$, Kingsley Badu², Anthony A Mensah ${ }^{3}$ and Stephen Y Gbedema ${ }^{4}$
}

\begin{abstract}
Background: Malaria and HIV/AIDS are the two most common infections in sub-Sahara Africa. There are hypotheses and study reports on the possible association between these two infections, hence the prevalence and outcome of their co-infection in an endemic population will be important in defining healthcare strategies. A cross sectional study was carried out at the Holy Family Hospital in Techiman, Ghana, between November 2011 and January 2012, to determine the prevalence of malaria among HIV sero-positive patients and its impact on hemoglobin levels.

Method: A total of 400 HIV sero-positive participants (292 females and 108 males) aged between 1 and 73 years were randomly sampled for the study. A questionnaire was administered and $2 \mathrm{ml}$ of venous blood samples were drawn for malaria parasites detection, CD4 count and haemoglobin level estimations.

Results: Malaria parasites were detected in $47(11.75 \%)$ of the participants. There was no statistically significant difference between the malaria prevalence rate of females (12.1\%) and males (10.2\%) $P=0.6047$. An overall anaemia prevalence of $67 \%$ was observed. Among participants with malaria the anaemia prevalence was $93.6 \%$. The CD4 cell count of all the participants ranged between 3 and 1604 cells/ $\mu$ l with a mean of $386.2( \pm 274.3)$ cells/ $\mu$ l. Participants with malaria had CD4 cell count ranged 3 and 512 Cells/ $\mu$ l with the mean being $186.33( \pm 133.49)$ Cells/ $\mu$ l. Out of 377 participants (all above 15 years) interviewed on knowledge of malaria transmission and prevention, 87.0\% had knowledge on transmission but only $8.5 \%$ use in bed nets.
\end{abstract}

Conclusion: It was revealed that almost all the patients with malaria infection were anemic.

Keywords: HIV/AIDS, CD 4 cells, Malaria co-infection, Anaemia, Anti-retroviral

\section{Introduction}

Malaria and Human immunodeficiency virus (HIV) infections are major public health problems in many parts of the world. Both infections kill millions of people each year with disproportionate heavy burden on Africa, India, Southeast Asia and South America [1].

Sub-Saharan Africa harbors $90 \%$ of the estimated 219 million cases that results in over 600,000 deaths annually $[2,3]$. Severe anemia as a result of malaria occurs in 1.5 to 6.0 million African children annually with mortality rate of nearly $10 \%$; respiratory distress, hypoglycaemia and other complications result in an additional 1-2 million

\footnotetext{
*Correspondence: scktaysammy9@yahoo.com

'Department of Clinical Microbiology, School of Medical Sciences, Kwame

Nkrumah University of Science and Technology, Kumasi, Ghana

Full list of author information is available at the end of the article
}

cases [4]. Malaria is a major cause of maternal anemia, which in turn is a risk factor for maternal mortality resulting in about $35 \%$ of preventable cases of low birth weight [4]. In Ghana malaria is still the leading cause of loss of days of healthy life [5] as it accounts for at least $20 \%$ of child deaths and over $45 \%$ of out-patient attendances [5].

Because of the high prevalence of HIV and malaria in sub-Saharan Africa, co-infections are common. Recent estimates put HIV/AIDS prevalence in Ghana at 2.9\% [6]. It is known that some 225,478 persons are living with the disease. Further to this, about 12,077 new infections are recorded annually with corresponding 15, 263 deaths [6,7]. By 2011, 59,007 people had access to anti-retroviral treatment; however this represented $57.9 \%$ of eligible patients [6]. Implying that an excess of $40 \%$ of people living with HIV/AIDS are left to die without getting access to 
anti-retroviral treatment. Notwithstanding the public huge health burden presented by these two infections, their interaction is still not completely understood [1].

Because of the high prevalence of HIV and malaria in sub-Saharan Africa, co-infections are common, Because of the geographic overlap between high-prevalence areas for malaria and HIV infection, there is growing evidence that the two infections may synergistically intensify each other, increasing incidence and complicating treatment efforts [3]. In a region of unstable malaria, HIV infection had an unexpectedly large association with the outcome of falciparum malaria where HIV infection was associated with severe/complicated malaria [8]. Recently Gupta and Shah using Sensitivity analysis and simulation has shown that malaria makes people move faster from HIV to AIDS class and reduce their life span. Radad and coworkers reported that an increase of one log in HIV viral load occurs during febrile malaria episodes enhancing susceptibility to malaria in HIV infected patients and this was found to facilitate the geographic expansion of malaria in areas where HIV prevalence was high [9].

As the number of malaria and HIV co-infection increased, it has become apparent that anti-retroviral drugs interact with the few anti-malaria drugs in use, complicating treatment efforts for both infections [10]. Malaria and HIV co-infection also result in interactions that adversely affect the outcome of both conditions, especially among pregnant women and infants born to HIV infected mothers [11]. Malaria [12] and HIV [13] individually are known to cause maternal anemia. Further to this, a number of researchers have reported a negative effect of the combined impact of HIV and malaria on maternal hemoglobin $(\mathrm{Hb})$ concentrations [14]. However, there is a dearth of information on the collective impact of HIVmalaria co-infection on the hemoglobin levels in the general population. Understanding the impact of HIV and malaria co-infection therefore, is important for determining approaches to treatment and prevention.

\section{Methods}

The study was conducted in the Holy Family Hospital; the only facility that provides ART services to HIV patients in the municipality. It has bed capacity of 167 beds. Patients diagnosed to have HIV/AIDS infection and who sought treatment at ART clinic at the Holy Family Hospital were the source population for the study. The drugs administered for the first line of treatment were Azidovudine (d4T), Lamivudine (3TC) plus Nevirapine or Efavirenz. Nelfinavir, Kaletra and Indinavir were occasionally used in combination with nucleoside based reverse transcriptase inhibitor drugs. The study was cross-sectional serological survey where HIV sero-positive patients attending ART Clinic at the hospital were randomly approached and invited to participate in the study provided they gave their consent. The study took place between November 2011 and January 2012.

Sample size was determined using the binomial model to estimate the confidence interval (CI). The HIV prevalence in the area is known to be less than 3\% so the malaria prevalence in the area which is higher was used to estimate the minimum sample size needed to achieve enough statistical power. Malaria prevalence in the area had previously been determined by Owusu-Adjei et al. to be about $60 \%$ in all age cohorts [15]. We calculated the sample size with a $95 \% \mathrm{CI}$ and precision level of $5 \%$ :

$$
n_{o}=\frac{Z_{a} P q}{d^{2}}
$$

In the equation below, $n$ is the sample size, $z$ is the critical value of the standard normal distribution at the $5 \%$ level (1.96), $\mathrm{p}$ is the estimated malaria prevalence (0.60), $q=1-p$, and $d$ is the precision level. This is used for a small population of up to 3,000. The sample size obtained was 369. A total of 400 HIV sero-positive individuals who sought care at the ART Clinic of the Holy Family Hospital in Techiman and were willing to participate in the study were recruited.

\section{Study area}

Techiman, is a major commercial town in the Brong Ahafo region linking not only most of Ghana's major cities, but also the republic of Togo, Burkina Faso and Cote D'Ivoire. It has an estimated total land area of about 669.7 square kilometers. According to the 2000 population and housing census, the population of the municipality was estimated to be 202,409 by December 2005, with an average growth rate of $3.0 \%$ per annum. Agriculture and related trades are the major economic activities in the municipality. Over half of the economically active population is engaged in these activities. This makes Techiman market the largest food crop market in Ghana. The municipality has twenty four (24) health care facilities; including two mission hospitals in Techiman, (i.e. Holy Family and Ahamadiya Hospitals), nine government health centers, four private maternity homes and three private clinics.

\section{Ethical clearance}

The study was approved by the Committee on Human Research Publication and Ethics from Kwame Nkrumah University of Science Technology and the management of Holy Family Hospital - Techiman. Consent of participants was also obtained prior to the study. All consenting patients attending the ART clinic were eligible for participation except infants less than 6 months. Refusal of some patients to participate in the study did not interfere with their routine care at the hospital. 


\section{Structured questionnaire}

A questionnaire, in both English and Twi (the local language) which included the basic socio- demographics of the study subjects as well as their knowledge and prevention of malaria was used. Two independent translators were engaged, one translated the English to Twi, the other was who had no prior copy of the English was tasked to translate the local language back into English. This was done to ensure the consistency of thought. No personal identifiers were included and individuals were given unique codes on the questionnaires and their laboratory specimens.

\section{Malaria parasite}

Laboratory investigation was conducted using the Thin Blood Film method. A drop of blood, 3-5 mm in diameter was put on a slide and spread with the corner of another slide to form a thin blood smear. The smear was thoroughly allowed to dry, fixed with methanol and stained with Giemsa stain for about 15 minutes. The stained smear was washed with running tap water, allowed to dry in air and examined microscopically for the presence of malaria parasites.

\section{HIV infection}

HIV test was conducted using First Response HIV Card Test 1-2.0 (Premier Medical Corporation Ltd, Mumbai, India). Reactive blood samples were confirmed with Oraquick Rapid HIV - 1/2 Antibody Test (OraSure Technologies Inc., Bethlehem, USA). Both test kits are immuno-chromatographic rapid tests for qualitative detection of antibodies specific to HIV in human serum, plasma or whole blood.

\section{CD4 count and Haemoglobin concentration}

The CD4 count of the study population was determined using Becton-Dickinson FASCount flow cytometer (BD Biosciences, California, USA) whilst the haemoglobin concentration was estimated with Sysmex XT - 2000i Haematology Analyzer (Sysmex Corporation, Hong Kong, China).

\section{Results}

\section{Socio-economic and demographic characteristics}

A total of 400 HIV sero-positive patients between 1 and 73 years were included in the study. Majority of them (73\%). the mean was between 30 and 34 years old. Most patients were married (38\%). Majority (37.1\%) had no formal education, with only $3 \%$ having had some tertiary education. $49.5 \%$ of the participants were unemployed with a further $30.7 \%$ being farmers. Further details are reported in Table 1.

\section{Hemoglobin level of patients (participants)}

Hemoglobin $(\mathrm{Hb})$ concentration levels of the patients ranged between 6.4 and $15.4 \mathrm{~g} / \mathrm{dl}$ with majority (18.0\%) of patients had $\mathrm{Hb}$ levels in the range of $12 .-12.9 \mathrm{~g} / \mathrm{dl}$. The mean $\mathrm{Hb}$ level of the patients was $10.8 \mathrm{~g} / \mathrm{dl}$ with mean (SD) for male and female as $11.5 \mathrm{~g} / \mathrm{dl}(2.26)$ and $10.56 \mathrm{~g} / \mathrm{dl}$ (2.22) respectively (Table 1 , Figure 1 ). Per the definition of anemia by the World Health Organization, hemoglobin levels $<13.0 \mathrm{~g} / \mathrm{dl}$ in adult men than $<12.0 \mathrm{~g} / \mathrm{dl}$ in adult women, an overall prevalence of $67 \%$ (268 out of 400) anemia was observed in this study. Majority of patients had mild to moderate anemia while severe anemia was observed in $2.8 \%$ of patients. Further details are reported in Figure 1 and Table 2.

\section{CD4 count of patients}

All patients studied had a CD4 cell count ranging from 3 1604 cells/ $\mu$ l. The mean (SD) of CD4 cell count of the patients was 386.2 (274.3) cells/ $\mu$ l. Majority of the participants (34.5\%) had CD4 count below 200 cells/ $\mu$ l (this represents the advanced stage of immuno-suppression). Another $33.3 \%$ had CD4 counts above 500cells/ $\mu$ l. The rest of the

Table 1 Socio-economic and demographic characteristics of patients (participants)

\begin{tabular}{|c|c|c|}
\hline Gender & Frequency & Percentage (\%) \\
\hline Male & 108 & 27.0 \\
\hline Female & 292 & 73.0 \\
\hline \multicolumn{3}{|l|}{ Age (years) } \\
\hline $1-4$ & 12 & 3.0 \\
\hline $5-9$ & 2 & 0.5 \\
\hline $10-14$ & 9 & 2.3 \\
\hline $15-24$ & 37 & 9.3 \\
\hline $25-34$ & 147 & 36.8 \\
\hline $35-44$ & 118 & 29.5 \\
\hline $45-60$ & 69 & 17.5 \\
\hline$>60$ & 5 & 1.25 \\
\hline \multicolumn{3}{|l|}{ Marital status } \\
\hline Married & 152 & $38 \%$ \\
\hline Single & 140 & $35 \%$ \\
\hline Divorced/Widowed & 108 & $27 \%$ \\
\hline \multicolumn{3}{|l|}{ Education } \\
\hline No formal education & 151 & 49.5 \\
\hline Primary education & 98 & 24.5 \\
\hline JHS/O-Level & 103 & 25.8 \\
\hline SHS/A-Level & 36 & 9.0 \\
\hline Tertiary & 12 & 3.0 \\
\hline \multicolumn{3}{|l|}{ Occupation } \\
\hline Unemployed & 198 & 49.5 \\
\hline Farmers & 123 & 30.8 \\
\hline Traders & 49 & 12.3 \\
\hline Other Skills & 30 & 7.5 \\
\hline
\end{tabular}




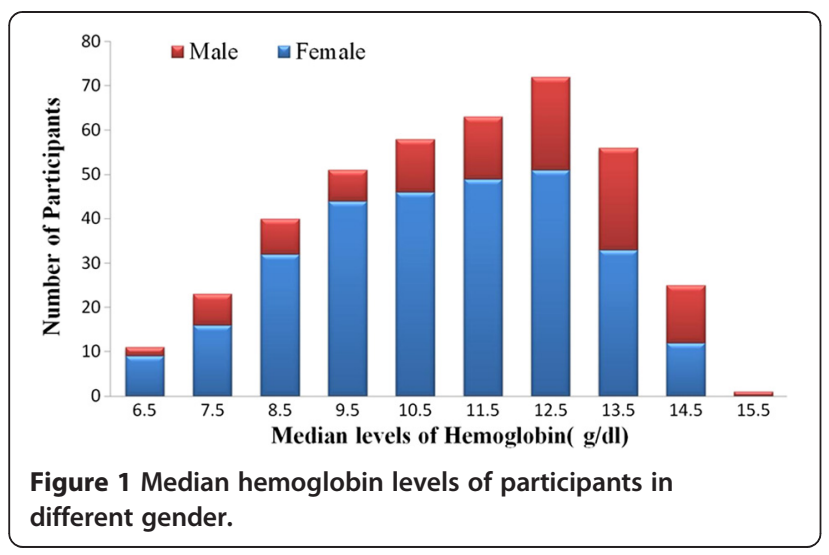

participants had CD4 counts between 200 and 499 cells/ $\mu$ l. further details of CD4 cell count based on gender differences are shown in the tables (Table 3).

\section{Malaria parasite prevalence}

An overall $11.75 \%(n=47)$ were found to be slide positive for malaria parasite with ages ranging from 2 years to 56 years. Malaria positivity was mostly within the age range of 30-34 years, followed by those in the age ranges of 25-29 years and 35-39 years. The least infected malaria patients were within the age ranges of 15 $19 y e a r s$ and $55-59$ years. Out of the 47 participants with patent parasitemia $36(76 \%)$ of them were females with only 11 being males (Figure 2).

\section{Malaria co infected participants and hemoglobin levels}

All participants who had malaria infection had a mean (SD) haemoglobin level to be $9.9 \mathrm{~g} / \mathrm{dl}$ (1.61). The hemoglobin level ranged was from $6.2 \mathrm{~g} / \mathrm{dl}$ to $13.2 \mathrm{~g} / \mathrm{dl}$. All the participants with malaria infection were anemic except for one participant who had $13.2 \mathrm{~g} / \mathrm{dl}$. Most of the study participants with malaria infection (13 out of 47) had hemoglobin level between the ranges of $10.0 \mathrm{~g} /$ $\mathrm{dl}-10.9 \mathrm{~g} / \mathrm{dl}$ (Figure 3). The prevalence of anemia with

Table 2 Hemoglobin levels in different gender

\begin{tabular}{llll}
\hline $\begin{array}{l}\text { Hemoglobin } \\
\text { (g/dl) }\end{array}$ & $\begin{array}{l}\text { Male } \\
\text { frequency (\%) }\end{array}$ & $\begin{array}{l}\text { Female } \\
\text { frequency (\%) }\end{array}$ & $\begin{array}{l}\text { Total } \\
\text { frequency (\%) }\end{array}$ \\
\hline $\mathbf{6 - 6 . 9}$ & $2(1.9)$ & $9(3.1)$ & $11(2.75)$ \\
$\mathbf{7 - 7 . 9}$ & $7(6.5)$ & $16(5.4)$ & $23(5.75)$ \\
$\mathbf{8 - 8 . 9}$ & $8(7.4)$ & $32(11.0)$ & $40(10.0)$ \\
$\mathbf{9 - 9 . 9 ( 1 2 . 7 5 )}$ & $7(6.5)$ & $44(15.1)$ & 51 \\
$\mathbf{1 0 - 1 0 . 9 ( 1 4 . 5 0 )}$ & $12(11.1)$ & $46(15.8)$ & 58 \\
$\mathbf{1 1 - 1 1 . 9 ( 1 5 . 7 5 )}$ & $14(13.0)$ & $49(16.8)$ & 63 \\
$\mathbf{1 2 - 1 2 . 9 ( 1 8 . 0 0 )}$ & $21(19.4)$ & $51(17.4)$ & 72 \\
$\mathbf{1 3 - 1 3 . 9 ( 1 4 . 0 0 )}$ & $23(21.3)$ & $33(11.3)$ & 56 \\
$\mathbf{1 4 - 1 4 . 9 ( 6 . 2 5 )}$ & $13(12.0)$ & $12(4.1)$ & 25 \\
$\mathbf{1 5 - 1 5 . 9}$ & $1(0.9)$ & $0(0.00)$ & $1(0.25)$ \\
\hline
\end{tabular}

Table 3 CD4 count of participants stratified according to gender

\begin{tabular}{llll}
\hline CD4 count & $\begin{array}{l}\text { Male } \\
\text { frequency (\%) }\end{array}$ & $\begin{array}{l}\text { Female } \\
\text { frequency (\%) }\end{array}$ & $\begin{array}{l}\text { Total } \\
\text { frequency (\%) }\end{array}$ \\
\hline$<200$ & $46(42.6)$ & $92(31.5)$ & $138(34.50)$ \\
$200-349$ & $23(21.3)$ & $54(18.5)$ & $77(19.3)$ \\
$350-499$ & $12(11.1)$ & $40(13.7)$ & $52(13.0)$ \\
$\geq 500$ & $27(25.0)$ & $106(36.3)$ & $133(33.3)$ \\
\hline
\end{tabular}

respect to gender was $90.9 \%$ and $94.4 \%$ for males and females respectively. Majority of the subjects with malaria infection 45 (89.4\%) had mild to moderate anemia with only $4.3 \%$ ( 2 out 47 ) having severe anemia. Severe anemia was observed in only females (Figure 3).

\section{Malaria infection and CD4 count}

All patients with malaria infection had CD4 cell count ranging from 3 cells $/ \mu$ lo 512 cells $/ \mu \mathrm{l}$ with mean (SD) CD4 cell count of 186.3 (133.5) cell/ul. Males had a mean of 209 (198.4) cells/ $\mu \mathrm{l}$ and females 178.7 (110.8) cells/ $\mu$ l. The majority, a whopping $66 \%$ of participants with patent malaria infection had their CD4 cell count below 200 cells $/ \mu \mathrm{l}$. With respect to gender, $63.6 \%$ (7 out of 11) males infected with malaria infection and $66.7 \%$ (24 out of 36) females infected with malaria infection had CD4 cell count less than 200 cells/ $\mu l$. Only one patient with malaria infection had CD4 cell count greater than or equal to 500 cells $/ \mu$ l and was observed in only males. Further details are provided in (Figure 4).

\section{Knowledge of malaria transmission and prevention}

Participants above 15 years of age $(n=377)$ interviewed on malaria transmission and prevention. $87.0 \%$ out of 377 of the participants claimed to have some knowledge about malaria transmission. Out of the 328 respondents that claimed to have knowledge about malaria, 216 (65.9\%) claimed that malaria could be transmitted from an infected person to a healthy person and the rest 112

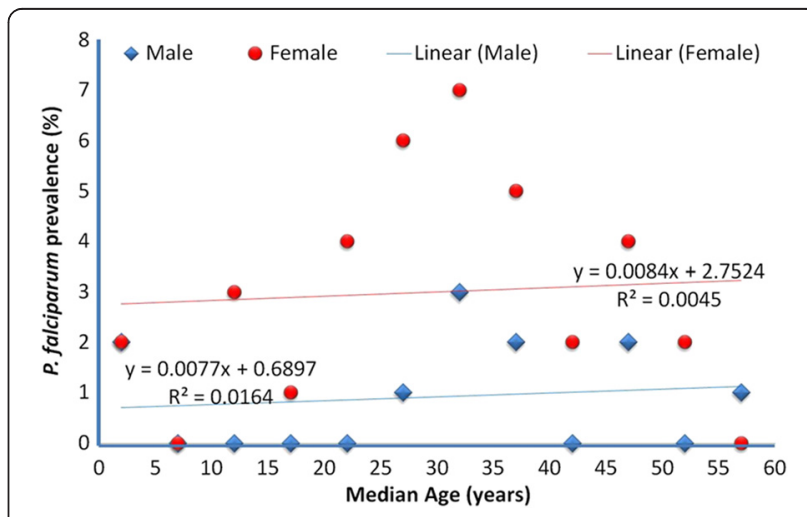

Figure 2 Age distribution of patients with malaria infection. 


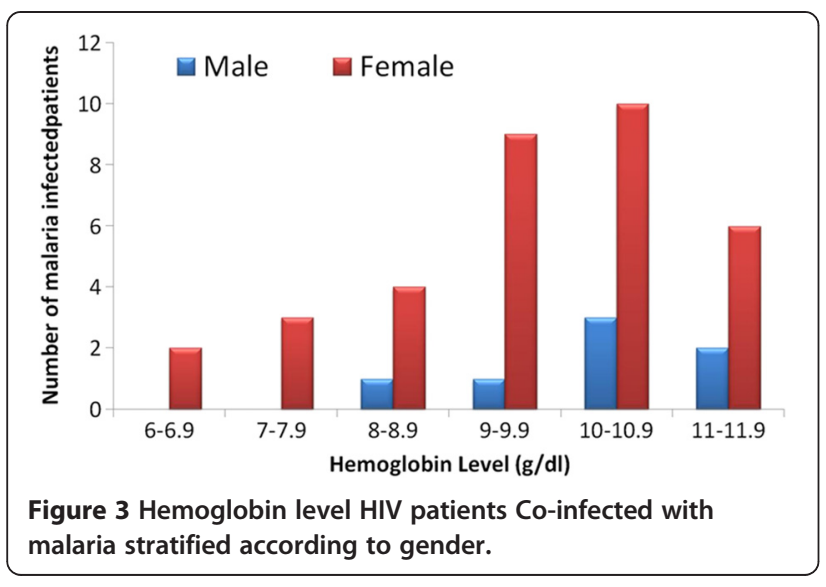

(34.1\%) claimed that either malaria cannot be transmitted from person to person or they had no idea at all. Among those who claimed that malaria is transmissible $(\mathrm{n}=216), 91.2 \%(\mathrm{n}=197)$ reported mosquito bite as a means of transmission (Table 4). About 92.7\% (304) of study participant who claimed to have knowledge about malaria reported that malaria is preventable. The most frequently mentioned method of prevention was environmental sanitation 286 (94.1\%) followed by taking antimalarial tablets $238(78.3 \%)$, bed nets $231(76.0 \%)$ and mosquito repellent 196 (64.5\%). The remaining 87 (28.6\%) reported various other methods like traditional cotton clothes, smoke and good diet. It was however surprising that with all the knowledge they claim to have, only $8.5 \%(\mathrm{n}=32)$ participants actually used bed net (Table 5).

\section{Discussion}

Accumulating data points to pathological interactions between HIV and malaria in co infected individuals. However, the public health consequences of this interaction have not been completely deciphered. Abu-Radad and coworkers in Kenya observed that a temporary one-

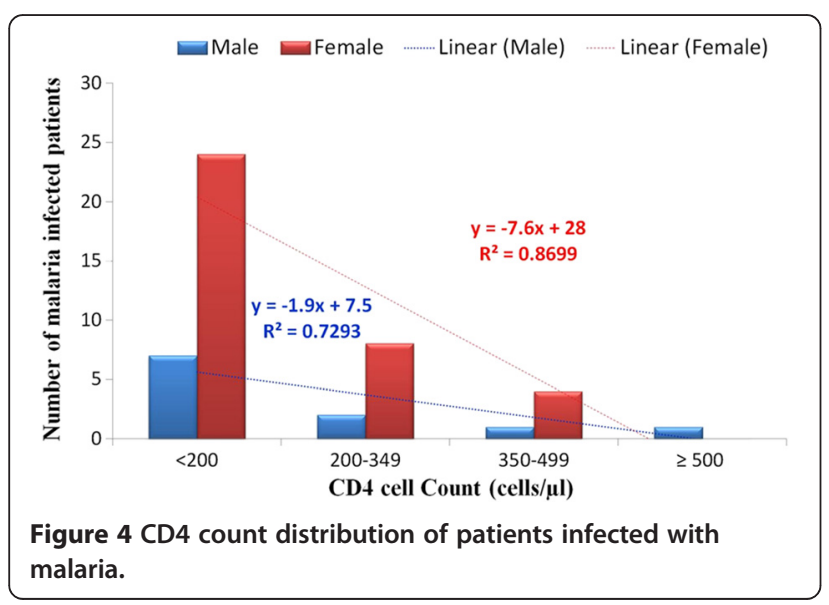

Table 4 Knowledge of malaria transmission and prevention

\begin{tabular}{|c|c|c|}
\hline Variable & $\begin{array}{l}\text { No. of } \\
\text { respondents }\end{array}$ & Frequency (\%) \\
\hline Knowledge about malaria & $(n=377)$ & \\
\hline Yes & & $328(87.0)$ \\
\hline No & & $49(13.0)$ \\
\hline Malaria transmissible? & $(n=328)$ & \\
\hline Yes & & $216(65.9)$ \\
\hline No & & 112(34.1) \\
\hline Means of malaria transmission & $(n=216)$ & \\
\hline Mosquito bite & & $197(91.2)$ \\
\hline Body contact & & $13(3.4)$ \\
\hline Respiratory route & & $24(11.1)$ \\
\hline Others & & $28(13.0)$ \\
\hline Malaria is preventable & $(n=328)$ & \\
\hline Yes & & $304(92.7)$ \\
\hline No & & $24(7.3)$ \\
\hline Preventive methods & $(n=304)$ & \\
\hline Antimalarial tablets & & $238(78.3)$ \\
\hline Bed nets & & $231(76.0)$ \\
\hline Mosquito repellents & & $196(64.5)$ \\
\hline Environmental sanitation & & $286(94.1)$ \\
\hline Others & & 87 (28.6) \\
\hline Use of bed nets & $(n=377)$ & \\
\hline Yes & & $32(8.5)$ \\
\hline No & & 345 (91.5) \\
\hline
\end{tabular}

log elevation in HIV viral load occurs during febrile malaria episodes; in addition, susceptibility to malaria is enhanced in HIV-infected patients [11].

In a one-time cross-sectional serological survey, the current study sought to determine malaria prevalence in HIV seropositive individuals; their CD4 count to identify the various stages of immuno-suppression and their hemoglobin levels to possibly associate the impact of the co-infection on the outcome of anemia in the study participants.

Generally malaria transmission in the forest zone of Ghana is intense $[6,15]$ with very high parasite prevalence up to $50 \%[15,16]$. But the overall malaria prevalence in

Table 5 CD4 cell count in participants co-infected with malaria

\begin{tabular}{llllc}
\hline CD4 Count & Frequency & Male & Female & $\mathbf{P}$-value \\
\hline$<200$ & $31(63.6)$ & $7(63.6)$ & $24(66.7)$ & 0.014 \\
$200-349$ & $10(21.3)$ & $2(18.2)$ & $8(22.2)$ & 0.235 \\
$350-499$ & $5(10.6)$ & $1(9.1)$ & $4(11.1)$ & 0.580 \\
$>500$ & $1(2.1)$ & $1(9.1)$ & $0(0.0)$ & 1.000 \\
\hline
\end{tabular}


this study was low; this may be due to the fact that the study was conducted during the drought months (NovemberJanuary) which coincide in Ghana with very low malaria transmission. However in comparison with similar studies in the African region, malaria prevalence in this study appears to be higher. The prevalence of malaria infection among HIV sero-positive patients in South Africa and Mozambique were lower [17,18]. But the observed prevalence is similar with a study done in Southeastern part of Nigeria in which the prevalence of malaria as a co-infection amongst asymptomatic HIV sero positive patients was $11.8 \%$ [19]. Malaria is known to cause an increase in transitory viral load while HIV causes more clinical malaria, higher parasitemia and higher rates of treatment failure in co-infected patients [11].

Females had relatively higher malaria infection compared with their male counterparts. This may be explained by their typical lifestyle in the community, where females tend stay out late during mosquito biting hours carrying out domestic activities. This has variously been reported elsewhere. Also, among the various age groups, it was determined that the age 30-34 years harbored more parasites than the other age groups. This was also confirmed with the high cumulative density index. However, prevalence of malaria infection was high in children within the age group of $0-4$ years in which out of $12 \mathrm{pa}-$ tients, four patients representing $33.3 \%$ had malaria infection. This is consistent with several studies in malaria endemic Africa [19] where prevalence of malaria infection in HIV children was high. However some studies have reported lower prevalence of malaria among non HIV children less than five years in the Brong-Ahafo region of Ghana [20].

The mean (SD) CD4 cell count of the patients was 386.2 (274.3). Males and females had CD4 count mean (SD) of 345.7(270.1) cells/ $\mu \mathrm{l}$ and 386.1(276.0) cells/ $\mu \mathrm{l}$ respectively. The difference in the mean CD4 count is due to the fact that HIV infection is detected earlier in females than their male counterparts. With the introduction of Prevention of Mother -To- Child Transmission of HIV (PMTCT) programme, women of child bearing age are screened for HIV infection during antenatal care or at obstetrics and gynecology clinics. Those who test positive are then incorporated into ART clinics while there is no similar program for males for the early detection of HIV.

CD4 cell count less than 200 cells/ $\mu$ l (signifying the terminal stage of HIV infection (AIDS) was seen in $34.5 \%$ patients. Obviously the major reason for this high proportion of AIDS is because of late presentation, largely due to the fact that we are yet to imbibe the culture of voluntary screening for early detection and treatment. Fear of stigmatization, lack of awareness and inadequate trained counseling personnel are some of the factors militating against voluntary screening. Many patients only seek medical attention and are diagnosed when HIV infection becomes complicated by AIDS defining illnesses. Majority of the patients (66.0\%) with malaria infection had CD4 cells count less than 200 cells $/ \mu$ l. This can be attributed to the well establishment that $\mathrm{CD}_{4}^{+} \mathrm{T}$ lymphocyte cells $<200$ cells/ $\mu \mathrm{l}$ is associated with a higher risk of opportunistic infection and poor disease progression [16].

Anemia is a frequent complication of infection with the human immunodeficiency virus, and could be clinically important. Multifactorial origin of anemia complicates determining its original cause and/or its proper treatment [21]. Using hemoglobin level of less than $13.0 \mathrm{~g} / \mathrm{dl}$ and $12.0 \mathrm{~g} / \mathrm{dl}$ as the cutoff point for anemia in males and females respectively, the overall prevalence of anemia among the patients was $67 \%$. The prevalence of anemia in this study is comparable with other studies (approximately $70 \%$ ) [22,23]. The incidence of anemia was strongly and consistently associated with the progression of HIV disease as measured by diagnosis of an AIDS-defining opportunistic illness and measurement of a CD4 count of 200 cells/ $\mu$ l. This association is most likely explained by the increasing viral burden as HIV disease progresses, which could cause anemia by increased cytokine mediated myelosuppression which impair erythropoiesis. Also several opportunistic organisms like Mycobacterium tuberculosis, Histoplasma, Cryptococcus, Coccidiodes, Pneumocystis carinii, and Leishmania have been shown to infiltrate the bone marrow and disrupt erythropoiesis [24]. Alternatively anemia may be a surrogate marker for some aspect of disease progression not captured by controlling for CD4 count and clinical AIDS diagnosis.

Several drugs used to combat HIV and its complications may contribute to the anemia that is seen in HIV infection. The administration of Zidovudine is recognized to cause anemia because of myelo-suppression [25].

Males and females did not show significant difference in the prevalence of anemia. Different studies have reported increase prevalence of anemia in females than males which were largely attributed to menstrual blood loss and to the drains on iron stores that occur with pregnancy and delivery [21]. However in this study, it was revealed that most males report to the ART clinic late by which HIV infection without antiretroviral therapy in the vast majority of infected males has progressively destroyed the immune system leading to opportunistic diseases and other condition that lead to anemia in HIV infection has advanced.

Majority of the HIV patients with anemia were mild to moderate anemia with few patients $(2.75 \%)$ with severe anemia. This is in agreement with studies by Meidani and co workers [21] where mild to moderate anemia 
was observed in majority of HIV patients with anemia in their studies. It was revealed that almost all the patients with malaria infection were anemic. This may be due to the clearance and or destruction of infected RBCs, the clearance of uninfected RBCs, erythropoietic suppression and dyserythropoiesis as reported as reported by others elsewhere by [26].

About $87 \%$ of the patients who responded to the questionnaire claimed to have some knowledge on malaria transmission in their area. This is an indication that the area selected for the study is malarious and known to have malaria transmission. More than half $(65.9 \%)$ of the respondents who claimed to know or have heard of malaria, reported malaria to be transmissible. The rest (34.1\%) reported that malaria cannot be transmitted from infected person to healthy ones or they have no idea about it at all. Among those who knew that malaria is transmitted, 91.2\% reported mosquito bite as a means of transmission. These are encouraging results and show the presence of a better knowledge in the method of malaria transmission however despite good knowledge about malaria transmission, this study also revealed evidence of knowledge gaps about malaria by some respondents misconception that that malaria is transmitted through drinking contaminated water, eating contaminated food, staying in the sun and working in rain.

Over $92.0 \%$ of the patients in this study reported that malaria is preventable. Over $75 \%$ of the patients who reported malaria are preventable stated taking tablets and use of bednets as methods of malaria prevention however only $8.5 \%$ use bednets. Discomfort, primarily due to heat, and perceived (low) mosquito density were the most widely identified reason for non-use of mosquito net. There were concerns by respondents about higher prices of mosquito nets to the extent of not being affordable by some respondents.

Malaria infection was high in HIV positive patients with CD4 count less than 200 cells/ $\mu$ l. Mild to moderate anemia was frequent in HIV positive patients but severe anemia was not prevalent in the study population. Almost all study participants with malaria were found to be anemic. This confirms the association between malaria and anemia. Future studies should compare prevalence of malaria co-infection among HIV/AIDS Seropositive individuals and non HIV/AIDS individuals with malaria.

\section{Competing interests}

The authors declare that they have no competing interests.

\section{Authors' contributions}

SCKT and AAM conceived the study, designed the study protocols. SCKT supervised laboratory tests. AAM collected laboratory specimen, carried out the test and wrote the first draft. SYG and KB participated in data analysis and manuscript development. All authors read and approved the manuscript.

\section{Acknowledgement}

We are grateful to the staff of Holy Family Hospital Techiman especially the staff of the Anti-Retroviral Treatment (ART) clinic and to Mr. Christopher Nkrumah (Methodist Hospital - Wenchi) for his help and support.

\section{Author details}

${ }^{1}$ Department of Clinical Microbiology, School of Medical Sciences, Kwame Nkrumah University of Science and Technology, Kumasi, Ghana. ${ }^{2}$ Department of Immunology, Noguchi Memorial Institute for Medical Research, College of Health Science, University of Ghana, Accra, Ghana. ${ }^{3}$ Department of Microbiology, Holy Family Hospital Techiman, Techiman, Ghana.

${ }^{4}$ Department of Pharmaceutics, Faculty of Pharmacy and Pharmaceutical Sciences, College of Health Sciences, Kwame Nkrumah University of Science and Technology, Kumasi, Ghana.

Received: 2 June 2014 Accepted: 12 January 2015

Published online: 07 March 2015

\section{References}

1. Asante PK, Zandoh C, Dery DB, Brown C, Adjei G, Antwi-Dadzie Y, et al. 'Malaria epidemiology in the Ahafo area of Ghana'. Malar J. 2011;10:211.

2. Palella FJ, Delaney KM, Moorman AC, Loveless MO, Fuhrer J, Satten GA, et al. Declining morbidity and mortality among patients with advanced human immunodeficiency virus infection. N Engl J Med. 1998;338(13):853-60.

3. Frontiera M, Myers AM. 'Peripheral blood and bone marrow abnormalities in the acquired immunodeficiency syndrome'. West J Med. 1987;147:157.

4. Huff B. HIV and malaria: Two intertwining epidemics'. Am Found Aids Res. 2000;6:1-5.

5. World Health Organization. World Malaria Report. Geneva: WHO; 2012.

6. Badu K, Brenya RC, Timmann C, Garms R, Kruppa TF. Malaria transmission intensity and dynamics of clinical malaria incidence in a mountainous forest region of Ghana. MWJ. 2013;4:14.

7. Murphy SC, Breman JG. Gaps in the childhood malaria burden in Africa: cerebral malaria, neurological sequelae, anemia, respiratory distress, hypoglycemia, and complications of pregnancy. Am J Trop Med Hyg. 2001;64:57-67.

8. Ministry of Health. Annual Report of the Ghana National Malaria Control Programme. Ghana: Ghana Health Service; 2006.

9. UNAIDS World AIDS Day report 2012, Regional fact sheets 2012. http://www. unaids.org/enresources/campaigns/20121120_globalreport2012/factsheet/

10. Sentinel Survey Report HIV. Republic of Ghana and Ghana Health Service. 2009.

11. Abu-Raddad $\amalg$, Patnaik P, Kublin JG. Dual infection with HIV and malaria fuels the spread of both diseases in sub-Saharan Africa. Science. 2006;314(5805):1603-6.

12. Grimwade K, French N, Mbatha DD, Zunga DD, Dedicoat M, Gilks CF. HIV-infection as a co-factor for severe falciparum malaria in adults living in a region of unstable malaria transmission in South Africa. AIDS. 2004;18:547-54.

13. Bretlinger PE, Behren CB, Micek MA. Challenges in the concurrent management of malarial and HIV in pregnancy in sub-Saharan Africa'. Lancet Infect Dis. 2006;6(2):100-11.

14. Guyatt HL, Snow RW. 'Malaria in pregnancy as an indirect cause of infant mortality in sub-Saharan Africa'. Trans R Soc Trop Med Hyg. 2001;95(6):569-76.

15. Owusu-Agyei S, Poku Asante K, Adjuik M, Adjei G, Awini E, Adams M, et al. Epidemiology of malaria in the forest-savanna transitional zone of Ghana. Malar J. 2009;8:220.

16. Browne ENL, Frimpong E, Sievertsen J, Hagen J, Hamelmann C, Dietz K, et al. Malariometric update for the rainforest and savannah of Ashanti region, Ghana. Ann Trp Med Parasitol. 2000;94(1):15-22.

17. Guyatt HL, Snow RW. The epidemiology and burden of Plasmodium falciparum-related anemia among pregnant women in sub-Saharan Africa. Am J Trop Med Hyg. 2001;64:36-44.

18. Mocroft A, Kirk O, Barton SE, Dietrich M, Proenca R, Colebunders R, et al. Anaemia is an independent predictive marker for clinical prognosis in HIV-infected patients from across Europe. EuroSIDA study group. AIDS. 1999;13:943-50.

19. FO T k, Parise ME, Verhoeff FH, Udhayakumar $\mathrm{V}$, Newman RD, MA V e, et al. The Burden of Co-infection with human immunodeficiency virus type 1 and malaria in pregnant women in Sub-Saharan Africa. Am J Trop Med Hyg. 2004;71(Suppl):41-54. 
20. Cohen C, Karstaedt A, Frean J, Thomas J, Govender N, Prentice E, et al. 'Increased prevalence of severe malaria in HIV-infected adults in South Africa'. Clin Infect Dis. 2005;41:1631-7.

21. Meidani M, Rezaei F, Maracy MR, Avijgan M, Tayeri K. 'Prevalence, severity, and related factors of anemia in HIV/AIDS patients'. J Res Med Sci. 2012;17(2):138-42.

22. Aase B, Sam P, Nina L, Bjorn B. 'Falciparum malaria and HIV-1 in hospitalized adults in Maputo, Mozambique: does HIV-infection obscure the malaria diagnosis?'. Malar J. 2008;7:252.

23. Onyenekwea CC, Ukibea N, Meludub SC, llikac A, Abohb N, Ofiaelid N, et al. 'Prevalence of malaria as co-infection in HIV-infected individuals in a malaria endemic area of southeastern Nigeria'. J Vector Borne Dis. 2007;44:250-4.

24. Hambleton J. 'Hematologic complications of HIV infection. Oncology. 1996;10:671-80.

25. Blake M, Sherer R. Management of the Adverse Effects of Antiretroviral Therapy and Medication Adherence. Clin Infect Dis. 2000;30 Suppl 2:S96-116. doi:10.1086/313859.

26. Lamikanra AA, Brown D, Potocnik A, Casals-Pascual C, Langhorne J, Roberts DJ. Malarial anaemia: of mice and men. Blood. 2007;110:18-28.

\section{Submit your next manuscript to BioMed Central and take full advantage of:}

- Convenient online submission

- Thorough peer review

- No space constraints or color figure charges

- Immediate publication on acceptance

- Inclusion in PubMed, CAS, Scopus and Google Scholar

- Research which is freely available for redistribution 